\title{
Connective tissue growth factor induction in a pressure-overloaded heart ameliorated by the angiotensin II type 1 receptor blocker olmesartan
}

\author{
Mutsumi Iwamoto ${ }^{1,2}$, Satoshi Hirohata ${ }^{1}$, Hiroko Ogawa ${ }^{1}$, Takashi Ohtsuki ${ }^{1}$, Ryoko Shinohata ${ }^{3}$, Toru Miyoshi ${ }^{1}$, \\ Faruk O Hatipoglu ${ }^{1}$, Shozo Kusachi ${ }^{3}$, Kazuhide Yamamoto ${ }^{2}$ and Yoshifumi Ninomiya ${ }^{1}$
}

Connective tissue growth factor (CTGF) is a secreted protein that regulates fibrosis. We hypothesized that CTGF is induced in a pressure-overloaded (PO) heart and that blocking the angiotensin II type 1 receptor would reduce CTGF expression. Accordingly, we administered olmesartan and compared its effects with other antihypertensive drugs in a PO heart. CTGF induction was determined in a rat PO model, and olmesartan, hydralazine or saline was continuously administered. The effects of olmesartan on CTGF induction, myocyte hypertrophy and fibrosis were evaluated. The effect of olmesartan on cardiac function was also examined in CTGF- and transforming growth factor-beta 1 (TGF- $\beta 1$ )-infused rats. CTGF was increased in the PO heart 3 days after aortic banding and was markedly distributed around the perivascular fibrotic area. After $\mathbf{2 8}$ days, blood pressure was not significantly different in the olmesartan and hydralazine groups, but olmesartan treatment reduced CTGF distribution in PO hearts. Olmesartan was associated with a significantly reduced myocyte hypertrophy index $(4.77 \pm 0.48$ for olmesartan and $6.05 \pm 1.45$ for saline, $P<0.01)$, fibrosis area (32.0 $\pm 15.5 \%$ compared with the saline group, $P<0.05)$ and serum TGF- $\beta 1$ level $\left(62.6 \pm 10.6 \mathrm{ng} \mathrm{ml}^{-1}\right.$ for olmesartan and $84.4 \pm 7.2 \mathrm{ng} \mathrm{ml}^{-1}$ for hydralazine, $\left.P<0.05\right)$. In addition, cardiac function was significantly preserved in the olmesartan group compared with the saline group. Finally, olmesartan ameliorated the cardiac dysfunction in CTGF- and TGF- $\beta 1$-infused rats. Olmesartan attenuated CTGF induction, reduced perivascular fibrosis and ameliorated cardiac dysfunction in a PO heart. Our results provide insight into the beneficial effects of olmesartan on PO hearts, independent of blood-pressure lowering.

Hypertension Research (2010) 33, 1305-1311; doi:10.1038/hr.2010.189; published online 14 October 2010

Keywords: angiotensin receptor; fibrosis; growth factor; hypertrophy

\section{INTRODUCTION}

Pressure overload (PO) causes myocyte hypertrophy, which leads to myocardial remodeling, including tissue fibrosis and subsequent heart failure. ${ }^{1,2}$ Connective tissue growth factor (CTGF) is a member of the CCN (cysteine-rich 61/chicken embryo fibroblast-10, CTGF/fibroblast-inducible secreted protein and nephroblastoma overexpressed) family of growth factors. ${ }^{3-5}$ CTGF is a profibrotic factor implicated in tissue fibrosis, including heart failure, and it mediates the fibrotic signal by transforming growth factor beta (TGF- $\beta$ ) activation. ${ }^{6-9}$ CTGF is stimulated by various factors, including TGF- $\beta$ and angiotensin II (Ang II). ${ }^{10-12}$ Ang II has an important role in both myocyte hypertrophy and myocardial fibrosis induced by PO. ${ }^{13}$ The inhibition of Ang II production and/or blockade of Ang II type 1 receptor have beneficial effects on the hypertensive heart, and are therefore widely used to treat patients in the clinical field. In this study, we examined the induction of CTGF expression in PO rat hearts and examined the effects of olmesartan, an Ang II type 1 receptor blocker (ARB), on CTGF mRNA induction and myocyte hypertrophy using a rat model. We then determined and compared the change in CTGF distribution, fibrosis and serum TGF- $\beta 1$ levels in an ARB-treated rat model.

\section{METHODS}

Animals and experimental protocols

All protocols involving experimental animals followed the local institutional guidelines for animal care, which are comparable to those in the Guide for the Care and Use of Laboratory Animals published by the Institute for Laboratory Animal Research (National Institutes of Health Publication No. 85-23, revised 1996). Male Sprague-Dawley rats (weighing 250-300 g) were anesthetized with sodium pentobarbital ( $50 \mathrm{mg} \mathrm{kg}^{-1}$, i.p.), and pressure overload was induced by banding the abdominal aorta at the suprarenal level as described previously. ${ }^{14,15}$ Briefly, the abdominal aorta was constricted at the suprarenal level with 4-0 silk by ligation with a blunted 19-gauge needle, which was then pulled out. The right carotid artery was cannulated, and aortic pressure was measured using an

${ }^{1}$ Department of Molecular Biology and Biochemistry, Okayama University Graduate School of Medicine, Dentistry and Pharmaceutical Sciences, Okayama, Japan; ${ }^{2}$ Department of Medicine and Medical Science, Okayama University Graduate School of Medicine, Dentistry and Pharmaceutical Sciences, Okayama, Japan and ${ }^{3}$ Department of Medical Technology, Okayama University Graduate School of Health Sciences, Okayama, Japan

Correspondence: Dr S Hirohata, Department of Molecular Biology and Biochemistry, Okayama University Graduate School of Medicine, Dentistry and Pharmaceutical Sciences, 2-5-1, Shikata-cho, Kita-ku, Okayama 700-8558, Japan.

E-mail: hirohas@cc.okayama-u.ac.jp

Received 6 April 2010; revised 10 August 2010; accepted 12 August 2010; published online 14 October 2010 
electromanometer (model AP260G; Nihon Koden, Tokyo, Japan) before the hearts were removed.

\section{Administration of antihypertensive drug}

Olmesartan ( $1 \mathrm{mg} \mathrm{kg}^{-1}$ per day), hydralazine ( $40 \mathrm{mg} \mathrm{kg}^{-1}$ per day) or saline was continuously administered using an osmotic pump (model 2ML2; Durect Corporation, Cupertino, CA, USA) after aortic banding. The osmotic pump was implanted subcutaneously into the backs of the rats. CTGF expression in the PO hearts of the hydralazine-administered group and the saline group ( $n=6$ for both) was compared.

\section{Administration of growth factors}

Recombinant human CTGF (PeproTech, Rocky Hill, NJ, USA; $11.25 \mu \mathrm{g} \mathrm{kg}^{-1}$ per day) and recombinant human latent TGF- $\beta 1$ (R\&D Systems, Minneapolis, MN, USA; $22.5 \mu \mathrm{g} \mathrm{kg}^{-1}$ per day) were continuously administered using an osmotic pump (2ML2) for 14 days without aortic banding. For the olmesartan group, olmesartan was continuously administered $\left(0.1 \mathrm{mg} \mathrm{kg}^{-1}\right.$ per day) using an osmotic pump.

\section{Echocardiography and tissue sampling}

Each rat was anesthetized with sodium pentobarbital $\left(15 \mathrm{mg} \mathrm{kg}^{-1}\right.$, i.p.), ketamine $\left(15 \mathrm{mg} \mathrm{kg}^{-1}\right.$, i.p.) and xylazine $\left(6 \mathrm{mg} \mathrm{kg}^{-1}\right.$, i.p.). Echocardiographic studies were performed before the surgical procedure and immediately before killing animals, as previously described. ${ }^{16,17}$ Cardiac function, including left ventricular ejection fraction was measured using ultrasound (ProSound SSD4000; Aloka, Tokyo, Japan). Rats were killed on days 1, 2, 3, 7 and 28 after aortic pressure had been measured. Body weight and heart weight were recorded in addition to myocyte length and width, which were then used to ascertain the degree of cellular hypertrophy, as described in previous studies. ${ }^{18,19}$ Briefly, one 5-mm thick section was obtained from an equatorial slice and it was stained with hematoxylin and eosin.

\section{RNA isolation}

Total RNA was extracted as previously described. ${ }^{20,21}$ After treatment, the total RNA of the cells was isolated using RNA STAT-60 reagent (TEL-TEST) and stored in aliquots at $-80^{\circ} \mathrm{C}$. Total RNA $(2 \mu \mathrm{g})$ was reverse-transcribed according to the manufacturer's protocol (Superscript II Amplification System for First Strand cDNA Synthesis; Invitrogen, Carlsbad, CA, USA). Contamination with genomic DNA was eliminated by DNase I treatment before cDNA synthesis, as previously described. ${ }^{22}$ The cDNA was diluted by fivefold before PCR amplification.

Quantitative real-time reverse transcription PCR (RT-PCR) analysis To examine changes in CTGF and TGF- $\beta 1$ mRNA levels, samples were analyzed using quantitative real-time RT-PCR with the comparative threshold cycle $(-\Delta \Delta C \mathrm{t})$ method as previously described. ${ }^{23-25}$ Briefly, mRNA coding for CTGF, TGF- $\beta 1$ and $18 \mathrm{~s}$ rRNA was quantified using the LightCycler rapid thermal cycler system (Roche Diagnostics, Lewes, UK) according to the manufacturer's instructions. A typical protocol took approximately $45 \mathrm{~min}$ and included a 10-min denaturation step, followed by 40 cycles of denaturation at $95^{\circ} \mathrm{C}$ for $10 \mathrm{~s}$, annealing at $65^{\circ} \mathrm{C}$ for $10 \mathrm{~s}$ and extension at $72^{\circ} \mathrm{C}$ for $20 \mathrm{~s}$.

The primers were as follows:

rat CTGF (208 bp): 5'-TGGACTGAACCGTATGATTG-3' (sense)

5'-GCTGGCTGCATCAACTTT-3' (antisense)

rat TGF- $\beta 1$ ( $300 \mathrm{bp}$ ): $5^{\prime}$-GCAACAACGCAATCTATGAC-3' (sense)

5'-CCTGTATTCCGTCTCCTT-3' (antisense)

rat 18s rRNA:5'-CCGCAGCTAGGAATAATGGA-3' (sense)

$5^{\prime}$-GAGTCAAATTAAGCCGCAGG-3' (antisense).

There was rarely significant primer dimer formation within the number of cycles required for quantification in a range of experimental samples. Each RT-PCR was repeated at least three times to verify reproducibility.

\section{Immunohistochemistry}

Immunohistochemistry of fresh frozen sections of the rat samples was performed as previously described. ${ }^{17}$ Cryostat-frozen sections were cut to a $5-\mu \mathrm{m}$ thickness, air-dried and fixed with acetone for $10 \mathrm{~min}$. Sections were then incubated with $5 \% \mathrm{H}_{2} \mathrm{O}_{2}$ in methyl alcohol for $30 \mathrm{~min}$, washed with phosphatebuffered saline for $5 \mathrm{~min}$ for three times and blocked with $1 \%$ bovine serum albumin for $60 \mathrm{~min}$. Paraffin blocks were cut into $5-\mu \mathrm{m}$ thick sections, deparaffinized in xylene, rehydrated and blocked with 5\% skim milk for human sections. Sections were then incubated with goat polyclonal anti-CTGF antibody (1:25; SC14939; Santa Cruz Biotechnology, Santa Cruz, CA, USA) overnight at $4{ }^{\circ} \mathrm{C}$ in a humid atmosphere and stained with a labeled highpolymer staining kit (Histofine Simple Stain rat MAX PO (G) kit; Nichirei, Tokyo, Japan) combined with a diaminobenzidine tetrahydrochloride or 3-Amino-9-ethylcarbazole (AEC) kit (Dako, Carpinteria, CA, USA) according to the manufacturer's instructions.

\section{Cardiac hypertrophy and fibrosis}

Heart sections were stained with hematoxylin and eosin, Azan and Picrosirius $\mathrm{red}^{26}$ to examine the extent of fibrosis. Sirius red (Direct Red 80; Sigma, St Louis, MO, USA) was dissolved in saturated picric acid solution $(0.1 \%)$ to prepare the staining solution. The samples were examined with a BX50 microscope (Olympus, Tokyo, Japan) equipped with an AxioVision system (CarlZeiss, Germany) using normal light, as previously reported. ${ }^{27}$ Cell width was measured at the nuclear level in longitudinally oriented cardiomyocytes using dedicated software (Image Proplus). ${ }^{28}$ Fibrotic areas in a given photomicrograph were determined with Win Roof image analysis software (Mitani Corporation, Fukui, Japan).

\section{Enzyme-linked immunosorbent assay (ELISA)}

Blood samples were drawn from each rat and serum was collected by microcentrifugation and stored in aliquots at $-30{ }^{\circ} \mathrm{C}$ until assayed by ELISA for TGF- $\beta 1$ (R\&D Systems). ELISA was performed as described in previous studies. ${ }^{29-31}$ Briefly, a monoclonal antibody to rat TGF- $\beta 1$ was used for capture, and a biotinylated polyclonal antibody was used for detection. Recombinant TGF- $\beta 1$ protein served as a standard. The lower limit of sensitivity was $31.2 \mathrm{pg} \mathrm{ml}^{-1}$, and the intra- and inter-assay coefficients of variation were $<3$ and $<10 \%$, respectively.

\section{Statistical analysis}

All values are given as the mean \pm s.d. Between-group variations were assessed using the two-tailed unpaired $t$-test. For multiple comparisons, analysis of variance was performed, and post-hoc analysis with Bonferroni's test was employed. $P$-values $<0.05$ were considered significant.

\section{RESULTS}

CTGF was induced in pressure-overloaded hearts

We first examined CTGF expression in the PO hearts in rats. Real-time quantitative RT-PCR analysis demonstrated that CTGF mRNA expression was significantly induced after 3 days of aortic banding (Figure 1a). Interestingly, CTGF production was observed in the PO heart and ascending aorta but not in the infrarenal descending aorta (data not shown), indicating that this induction was not due to systemic hormonal factors. TGF- $\beta 1$ mRNA gradually increased in the PO heart and significantly increased 7 days after aortic banding (Figure 1b). At the protein level, CTGF was distributed in the perivascular fibrosis area in the PO heart 3 days after banding, and CTGF-positive signals were observed in both the perivascular fibrotic area and the intracellular fibrotic area after 7 days of banding (Figure 1c).

\section{Effect of olmesartan on cardiac hypertrophy in the pressure-overloaded heart}

We then treated PO rats with antihypertensive drugs and examined the effect on cardiac hypertrophy. Olmesartan was used and compared with hydralazine- and saline-administered groups $(n=6$ in each group). As shown in Table 1, there was a significant increase in systolic blood pressure in the saline-administered group. However, 
a

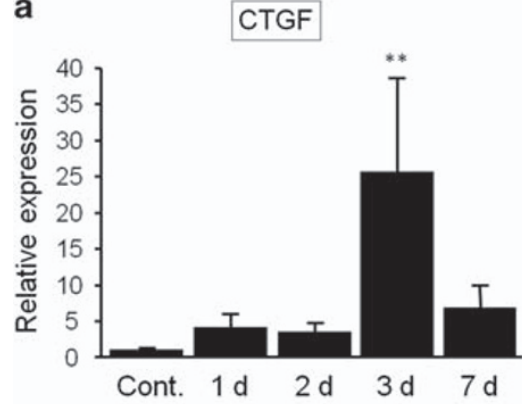

b

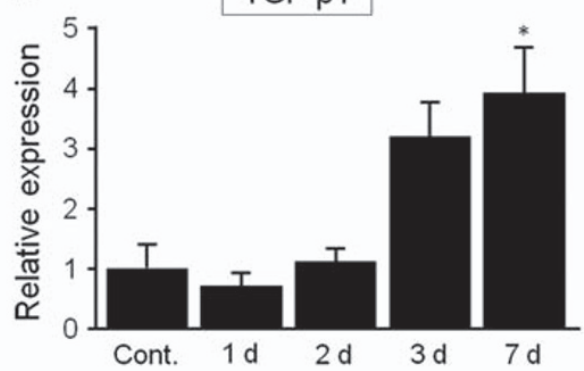

C

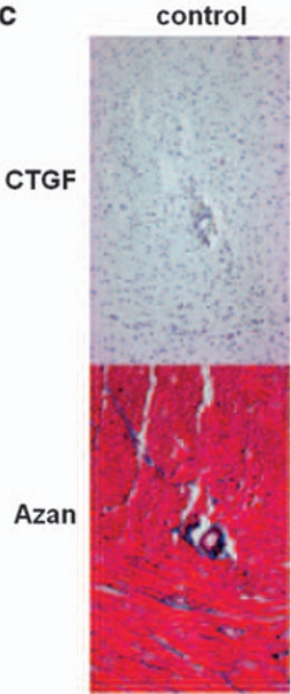

1d

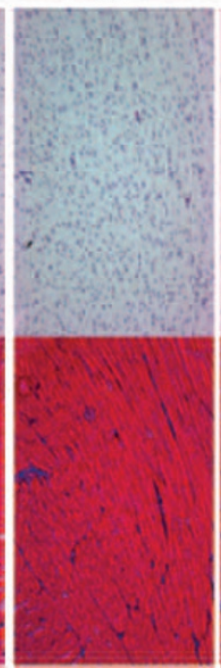

$2 d$

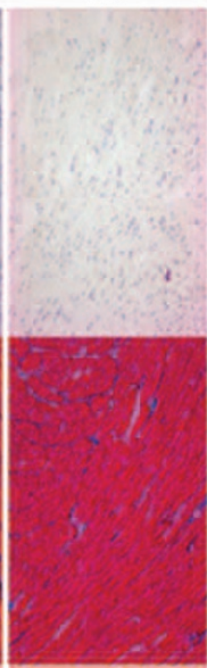

$3 d$

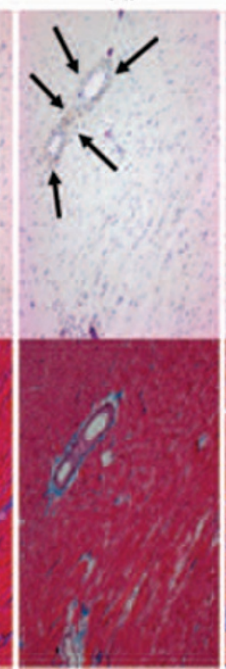

$7 d$

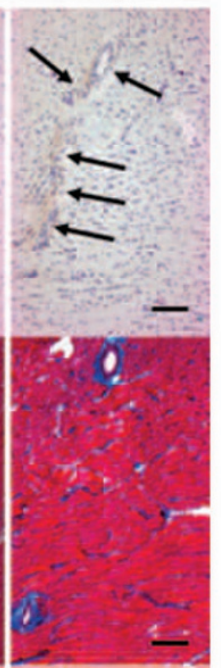

Figure 1 Induction of CTGF and TGF- $\beta$ mRNA and CTGF distribution in rat pressure-overloaded (PO) hearts. (a) Quantitative real-time RT-PCR analysis demonstrated that CTGF mRNA expression was significantly increased after 3 days of aortic banding (** $P<0.01$ vs. control group) (Cont., control group). (b) Quantitative real-time RT-PCR analysis of TGF- $\beta 1$ mRNA expression showed that TGF- $\beta$ mRNA was significantly increased after 7 days ( ${ }^{*} P<0.05$ vs. control group). (c) Time course of CTGF distribution in the PO heart. CTGF-positive signals (brown) were observed in the perivascular fibrotic area at 3 days (arrows) and in both perivascular and intracellular fibrotic areas after 7 days of banding (arrows). Azan staining (blue) demonstrates a fibrotic area in the adjacent section after aortic banding (bottom). Scale bar: $100 \mu \mathrm{m}$.

Table 1 Hemodynamic measurements and organ weights

\begin{tabular}{lccc}
\hline & Saline & Hydralazine & Olmesartan \\
\hline 7 day & & & \\
IVSd (mm) & $1.62 \pm 0.15$ & $1.45 \pm 0.10^{\#}$ & $1.30 \pm 0.11^{\# \#, *}$ \\
LVPW (mm) & $1.68 \pm 0.13$ & $1.57 \pm 0.10$ & $1.35 \pm 0.08_{\# \#, * *}$ \\
SBP (mm Hg) & $142 \pm 11$ & $109 \pm 10^{\# \#}$ & $109 \pm 10^{\# \#}$ \\
HW/BW $\left(\times 10^{-3}\right)$ & $4.01 \pm 0.62$ & $4.32 \pm 0.51$ & $3.73 \pm 0.33^{*}$ \\
& & & \\
28 day & & & \\
IVSd (mm) & $1.57 \pm 0.08$ & $1.70 \pm 0.14$ & $1.22 \pm 0.08^{\# \#, * *}$ \\
LVPW (mm) & $1.57 \pm 0.08$ & $1.73 \pm 0.11^{\#}$ & $1.28 \pm 0.08^{\# \#, * *}$ \\
SBP $(\mathrm{mm} \mathrm{Hg})$ & $135 \pm 5$ & $114 \pm 5^{\# \#}$ & $109 \pm 10^{\# \#}$ \\
$\quad$ HW/BW $\left(\times 10^{-3}\right)$ & $3.50 \pm 0.55$ & $4.00 \pm 0.40$ & $3.05 \pm 0.17^{*}$ \\
Myocyte hypertrophy index & $6.05 \pm 1.45$ & $5.60 \pm 1.20$ & $4.77 \pm 0.48^{\# \#, *}$ \\
\hline
\end{tabular}

Abbreviations: BW, body weight; HW, heart weight; IVSd, end-diastolic interventricular septal thickness; LVPW, end-diastolic left ventricular posterior wall thickness; SBP, systolic blood pressure.

${ }^{\#} P<0.05$ vs. saline; ${ }^{\#} P<0.01$ vs. saline; ${ }^{*} P<0.05$ vs. hydralazine; ${ }^{* *} P<0.01$ vs. hydralazine.

blood pressure was significantly ameliorated in rats treated with olmesartan in comparison with the saline-treated group (109 \pm 10 and $135 \pm 5 \mathrm{~mm} \mathrm{Hg} ; P<0.01)$ after 28 days of banding. The left ventricular hypertrophy in the olmesartan-treated group after 28 days of banding, as determined by echocardiography (that is, end-diastolic interventricular septal thickness) was significantly reduced as compared with the saline-treated group $(1.22 \pm 0.08$ and $1.57 \pm 0.08 \mathrm{~mm} ; P<0.01)$. On the other hand, when rats were treated with hydralazine, systolic blood pressure decreased to levels similar to those in the olmesartan group, but end-diastolic interventricular septal thickness was increased $(1.70 \pm 0.14 \mathrm{~mm})$. The myocyte hypertrophy index was significantly worse in the hydralazine group than that in the olmesartan-treated group (5.60 \pm 1.20 and $4.77 \pm 0.48, P<0.05$ ), indicating that the hypertrophic change in the PO heart was blood pressure independent.

\section{Effect of olmesartan on CTGF expression, cardiac fibrosis and function in the PO heart}

We next examined CTGF expression and the extent of fibrosis in PO rats in the saline- and olmesartan-treated groups. In saline-treated rats, CTGF was observed around vascular smooth muscle cell (VSMC) layers in the PO heart after 7 days of aortic banding (data not shown). In contrast, there was no significant positive signal for CTGF in the olmesartan-treated heart (data not shown). At 28 days post-aortic banding, considerable CTGF distribution around the VSMC layers in the PO heart was observed in saline-treated rats (Figures $2 \mathrm{a}$ and $\mathrm{d}$ ), in contrast with moderate CTGF expression around the VSMC layers 


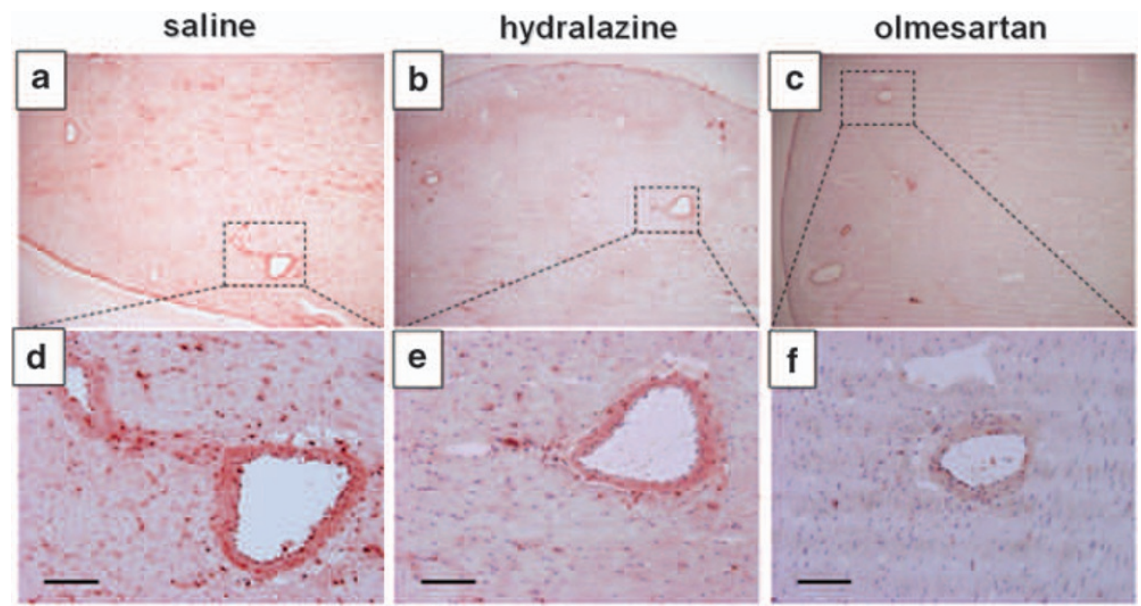

Figure 2 Effect of antihypertensive drugs on CTGF distribution in rat PO hearts. (a) Saline was administered to the PO heart for 28 days, using an osmotic pump. Considerable distribution of CTGF-positive signals (red) was observed around the perivascular area and interstitial fibrotic area. The dotted boxed area shows the area that was observed at higher magnification in (d). (b) Hydralazine was administered to the PO heart for 28 days, using an osmotic pump. CTGF-positive signals (red) were observed around the perivascular area and interstitial space. The dotted boxed area shows the area observed at higher magnification in (e). (c) Olmesartan was administered to the PO heart for 28 days, using an osmotic pump. CTGF-positive signals (red) were faint around the perivascular area and interstitial space. The dotted boxed area shows the area observed at higher magnification in (f). (d) Higher magnification of the vascular area (boxed region) in A. CTGF-positive signals (red) was distinctly observed around the vessels and interstitial space. (e) Higher magnification of the vascular area (boxed region) in (b). CTGF-positive moderate signals (red) were observed around the vessels and interstitial space. (f) Higher magnification of the vascular area (boxed region) in (c). CTGF-positive moderate signals (red) were faint around the vessels and interstitial space. Scale bar: $100 \mu \mathrm{m}$.

in the hydralazine-treated heart (Figures $2 \mathrm{~b}$ and $\mathrm{e}$ ). The olmesartantreated heart showed clear signals of CTGF around the VSMC layers (Figures $2 \mathrm{c}$ and $\mathrm{f}$ ). Cardiac hypertrophic change was significantly attenuated in the olmesartan group compared with the blood pressure-matched hydralazine group after 28 days of banding (Table 1). The extent of fibrosis in the PO heart was quantitatively analyzed using Masson's trichrome staining. The fibrotic area was significantly reduced in the olmesartan-treated group compared with the salinetreated group (Figures $3 \mathrm{a}-\mathrm{g}$ ). We then examined the serum TGF- $\beta 1$ levels in olmesartan-treated PO hearts and compared them with the hydralazine-treated PO hearts ( $n=6$ olmesartan and $n=3$ hydralazine). As shown in Figure 4, serum TGF- $\beta 1$ levels were significantly decreased in the olmesartan-treated group compared with the hydralazine-treated group $(P<0.05)$. Next, we examined the ejection fraction of the PO hearts in each group. As shown in Figure 5a, the ejection fraction in the sham-operated group was $88.4 \pm 2.6 \%$, and the ejection fraction in the olmesartan group was significantly preserved compared with the saline group.

\section{Effect of olmesartan on cardiac function in the CTGF- and TGF-p1-infused heart}

Finally, we examined the cardioprotective effect of olmesartan in CTGF- and TGF- $\beta 1$-infused hearts. After 14 days of continuous administration of growth factors, cardiac function was reduced, and olmesartan ameliorated this cardiac dysfunction (Figure 5b).

\section{DISCUSSION}

This study demonstrated that CTGF expression and fibrotic change were induced in the PO heart, and these effects were ameliorated by olmesartan treatment.

The method we followed for our PO model is well established, and the blood pressure data in our model are consistent with previous reports, ${ }^{15,32,33}$ indicating that our procedures are valid. When the aorta is constricted and PO is induced, one of the early events is an adaptive change of the vessels in the PO heart, referred to as perivascular fibrosis. In this study, we focused on perivascular change because this adaptive change results in consecutive pathological cardiac hypertrophy and heart failure from PO. ${ }^{34}$ Perivascular fibrosis is mediated by several factors, including neurohumoral factors and mechanical stress on the vessel wall. Macrophages, fibroblasts and VSMCs have roles in this process. In the PO heart, VSMCs proliferated and produced profibrotic molecules, such as TGF- $\beta 1$ and CTGF. VSMC proliferation is regulated by an $\mathrm{AT}_{1}$ receptor-dependent mechanism in the PO heart, following an Ang II infusion model. ${ }^{35}$ Tokuda et al. ${ }^{36}$ reported that aortic constriction-induced PO enhanced angiotensin-converting enzyme activity after 1 day, peaked at 3 days and then fell, but to levels significantly higher than the basal level, by 14 days. Kai et al. ${ }^{15}$ reported that $\mathrm{PO}$-induced oxidative stress and perivascular fibrosis were attenuated by candesartan. Our findings that olmesartan attenuated CTGF induction and perivascular fibrosis in PO hearts are in line with these reports. These data suggest that ARB is likely to be beneficial in blocking early changes (that is, perivascular fibrotic response) in the PO heart.

We compared the effects of olmesartan with hydralazine in this study because hydralazine has been widely used as a blood pressurematched control in animal models. ${ }^{37}$ ARB is widely used as an antihypertensive drug, and losartan and telmisartan have been reported to ameliorate interstitial and perivascular fibrosis; however, left ventricular hypertrophy was only partially preserved in the saltinduced hypertension model. ${ }^{38}$ In this study, we examined the effect(s) of olmesartan, while controlling blood pressure and compared it with blood pressure-matched rats treated with another antihypertensive drug, hydralazine. Although the decrease in blood pressure was similar in the olmesartan- and hydralazine-treated groups, there were significant differences in cardiac hypertrophy and perivascular fibrosis between the two groups. Therefore, the inhibition of CTGF and perivascular fibrosis by olmesartan is an independent blood pressure-lowering mechanism.

Left ventricular PO resulting from hypertension activates a wide range of signaling pathways. In addition to loading conditions, 

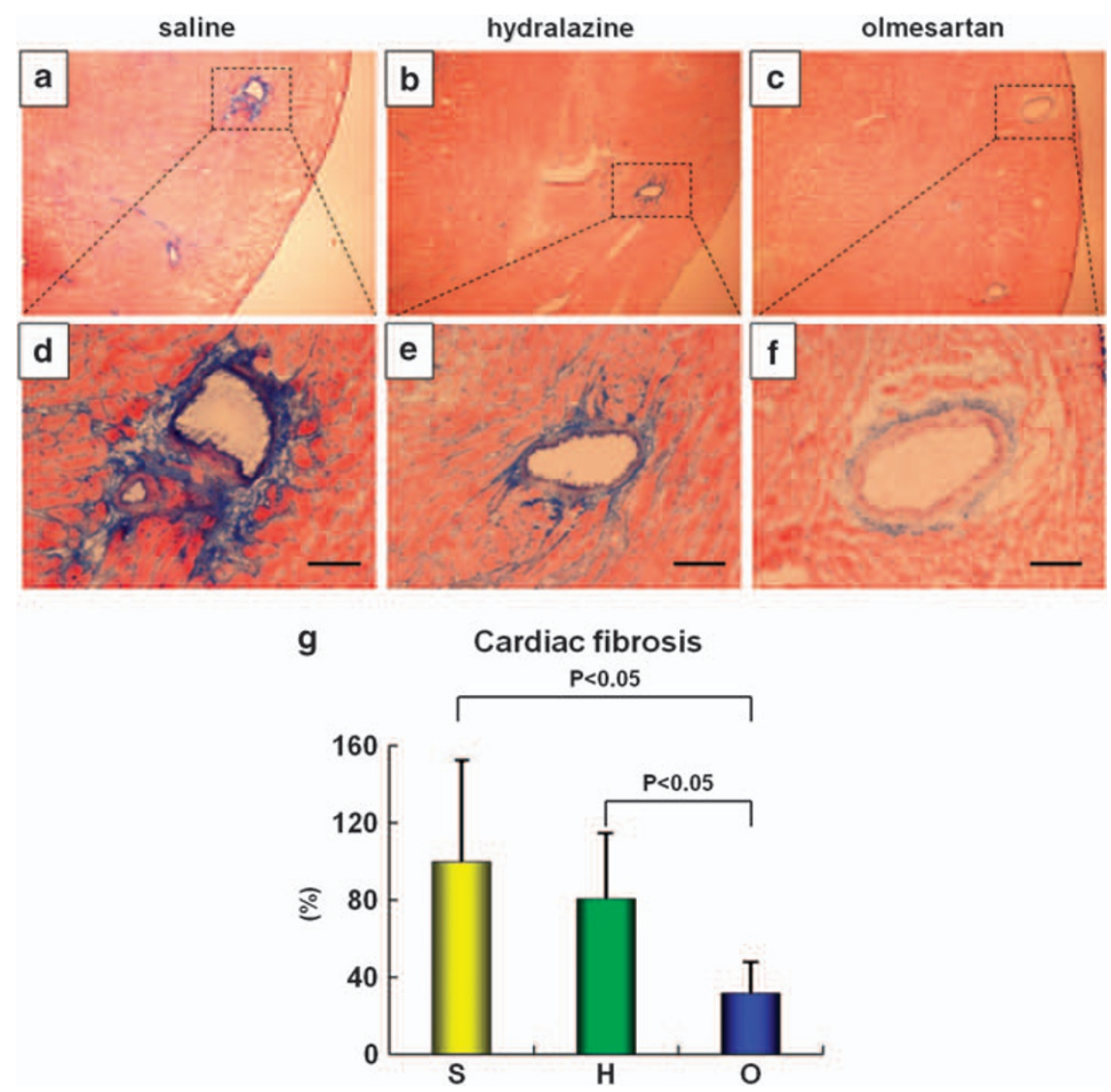

Figure 3 Effect of antihypertensive drug on fibrotic change in rat PO hearts. Azan staining was performed to identify fibrotic change (blue). (a) Saline was administered to the PO heart for 28 days using an osmotic pump. Perivascular and interstitial fibrotic areas are shown (blue). The dotted boxed area shows the area observed at higher magnification in (d). (b) Hydralazine was administered to the PO heart for 28 days using an osmotic pump. Fibrosis (blue) was observed around the perivascular area and interstitial space. The dotted boxed area shows the area observed at higher magnification in (e). (c) Olmesartan was administered to the PO heart for 28 days using an osmotic pump. Fibrotic change (blue) was faint around the perivascular area and interstitial space. The boxed area in dots shows the area observed at higher magnification in (f). (d) Higher magnification of the vascular area (boxed region) in (a). (e) Higher magnification of the vascular area (boxed region) in (b). (f) Higher magnification of the vascular area (boxed region) in (c). Scale bar: $100 \mu \mathrm{m}$. (g) Quantification of the fibrotic area in PO hearts. The result of Azan staining (blue color) of PO hearts (28 days, $n=6$ in each group) was quantified in each group using image analysis software. The fibrotic areas in the saline-treated PO hearts were considered to be 100, and the relative fibrotic areas in each group are shown ( $\mathrm{S}$, saline; $\mathrm{H}$, hydralazine; $\mathrm{O}$, olmesartan). Note that the olmesartan group showed a significant reduction of the fibrotic area compared with the saline-treated group.

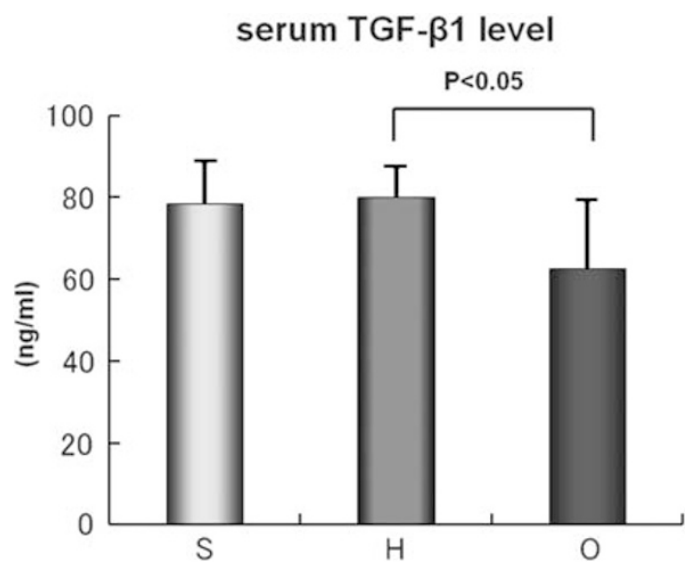

Figure 4 Serum TGF- $\beta 1$ levels in the PO heart. Serum was collected 28 days after aortic constriction, and TGF- $\beta 1$ level was determined by ELISA in the hydralazine and olmesartan groups (S, saline; $\mathrm{H}$, hydralazine; 0 , olmesartan). it appears that the local release of neuroendocrine ligands can modulate myocyte hypertrophy and function along with extracellular matrix reorganization. ${ }^{39}$ It has been shown that Ang II can activate the Smad pathway, which has a role in the regulation of CTGF associated with mitogen-activated protein kinase signaling. ${ }^{10}$ Another group reported that SB203580, a p38 mitogen-activated protein kinase inhibitor, diminished Ang II-induced Smad2 phosphorylation. ${ }^{40}$ Xia et al. ${ }^{41}$ reported activation of the Smad signaling pathway after aortic constriction in a transverse aortic constriction model and Gao et al. ${ }^{42}$ reported activation of the Smad signaling pathway in the Ang IIinfused heart. These data suggest that the Smad pathway might be associated with CTGF induction in the PO heart.

CTGF development in a failing heart is a general response to evolving heart failure. Koitabashi et al. ${ }^{43}$ reported that plasma CTGF levels were elevated in patients with heart failure. In the myocardial infarction model, CTGF induction was observed, and losartan prevented the induction of myocardial CTGF mRNA in rats after myocardial infarction and attenuated ventricular hypertrophy. ${ }^{12}$ In the streptozocine diabetic heart, candesartan treatment has been 
a
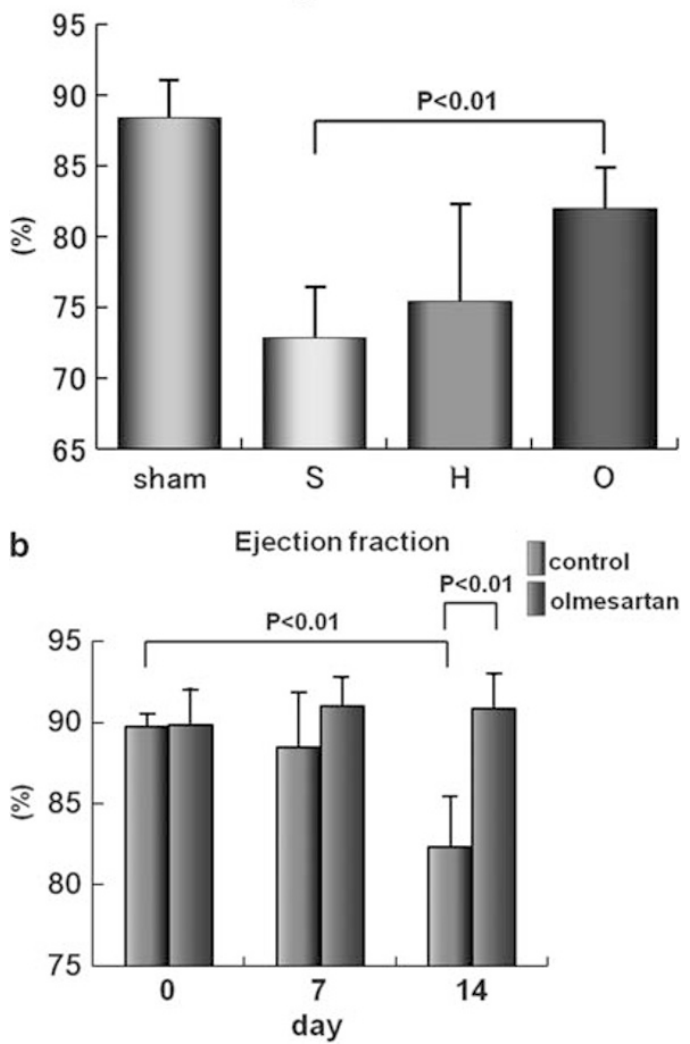

Figure 5 (a) Effect of olmesartan on cardiac function in the PO heart. The ejection fraction was measured in the sham-operated and PO hearts ( $n=6$ in each group) after 28 days of aortic constriction (sham, sham heart; $\mathrm{S}$, saline; $\mathrm{H}$, hydralazine; $\mathrm{O}$, olmesartan). Note that systolic function was preserved in the olmesartan group after 28 days of constriction, in contrast to the saline- and hydralazine-treated hearts. (b) Effect of olmesartan on cardiac function in the CTGF- and TGF- $\beta 1$-infused hearts. After 14 days of continuous administration of growth factors, cardiac function was reduced in the nontreated rats (control), and olmesartan treatment (olmesartan) ameliorated this cardiac dysfunction.

reported to ameliorate CTGF expression and ventricular remodeling. ${ }^{44}$ Duisters et al. ${ }^{45}$ reported that CTGF is regulated by two major cardiac microRNAs, which were downregulated in several models of cardiac hypertrophy and heart failure. Recently, Panek et al. ${ }^{46}$ reported that cardiomyocyte-specific CTGF transgenic mice developed cardiac dysfunction but did not develop cardiac fibrosis. These reports support the significant role of CTGF in heart failure. Our results demonstrate that olmesartan attenuated CTGF induction in the PO heart and ameliorated both cardiac hypertrophy and perivascular fibrosis compared with blood pressure-matched controls. The discrepancy in fibrosis may be explained by different experimental methods. In our experimental model, the major source of CTGF was cardiac VSMC, not myocytes, and fibrosis was mainly perivascular. Therefore, the sizable role of VSMCs and perivascular fibrosis in the PO heart may have been modulated by olmesartan in this study. Because the beneficial effects of angiotensin-converting enzyme/ARB in heart failure are recognized, the cardioprotective effects of olmesartan may be because of its targeting of CTGF, an important factor in Ang IIinduced myocardial remodeling.

Our study demonstrated a reduction in serum TGF- $\beta 1$ levels in the PO heart with ARB treatment compared with the hydralazine-treated group. As previously shown in other diseases, serum or plasma TGF$\beta 1$ levels may be a biomarker for wound healing and fibrosis. ${ }^{47-49}$ El-Agroudy et al..$^{50}$ reported that losartan significantly decreased plasma TGF- $\beta 1$ levels in hypertensive renal transplant patients. Although careful observation of TGF- $\beta 1$ levels in a larger number of samples is needed, TGF- $\beta 1$ measurement may be useful for monitoring developing heart failure.

There are several limitations to this study. First, the attenuation of CTGF induction may be attributed to the attenuation of cardiac hypertrophy and fibrosis. Because olmesartan has antihypertrophic and antifibrotic effects, the CTGF attenuation may be a secondary result of reducing hypertrophy and/or fibrosis. However, rosiglitazone has been to shown to attenuate CTGF expression in the Ang IIstimulated SMC in vitro. ${ }^{42}$ In addition, olmesartan showed a cardioprotective effect in a CTGF- and TGF- $\beta 1$-infusion rat model. Given these data, we conclude that CTGF is likely to be one of the targets of olmesartan. Second, TGF- $\beta$ (that is, TGF- $\beta 1$, TGF- $\beta 2$ and TGF- $\beta 3$ ) activation as a consequence of CTGF induction was not confirmed. We did not primarily deal with the cascade of CTGF and TGF- $\beta$ activation but focused on the effect of olmesartan on the PO heart by comparing blood pressure-matched controls. The signaling cascade of TGF- $\beta$ activation, including the phosphorylation of $S \operatorname{mad} 2 / 3$, has been well characterized. Although we did not examine TGF- $\beta$ activation in the PO heart, a previous study demonstrated late induction of TGF- $\beta 1$ in the PO heart, ${ }^{41}$ and our real-time RT-PCR results confirmed these data. In addition, serum TGF- $\beta 1$ levels were better attenuated by olmesartan than hydralazine in our model (data not shown), suggesting that olmesartan treatment reduced TGF- $\beta$ induction in our rat model.

In conclusion, we demonstrate olmesartan's protective effect on the PO heart by CTGF attenuation, showing that its ameliorative effects on cardiac dysfunction go beyond than lowering the blood pressure.

\section{ACKNOWLEDGEMENTS}

We thank Dr Toshitaka Oohasi, Dr Tomoko Yonezawa, Dr Kazuya Koten, Kadir Demircan and other members of our department for stimulating discussions and comments. We are also grateful to Tomoko Maeda, Ayako Takeuchi and Asuka Terasako for their technical help. This work was supported in part by funding from a grant-in-aid for scientific research from the Japan Society for the Promotion of Science (grant 20390399 to SH and 21790537 to RS).

1 Ruwhof C, van der Laarse A. Mechanical stress-induced cardiac hypertrophy: mechanisms and signal transduction pathways. Cardiovasc Res 2000; 47: 23-37.

2 Hein S, Arnon E, Kostin S, Schonburg M, Elsasser A, Polyakova V, Bauer EP, Klövekorn WP, Schaper J. Progression from compensated hypertrophy to failure in the pressureoverloaded human heart: structural deterioration and compensatory mechanisms. Circulation 2003; 107: 984-991.

3 Takigawa M. CTGF/Hcs24 as a multifunctional growth factor for fibroblasts, chondrocytes and vascular endothelial cells. Drug News Perspect 2003; 16: 11-21.

4 de Winter $\mathrm{P}$, Leoni $\mathrm{P}$, Abraham D. Connective tissue growth factor: structure-function relationships of a mosaic, multifunctional protein. Growth Factors 2008; 26: 80-91.

5 Shi-Wen X, Leask A, Abraham D. Regulation and function of connective tissue growth factor/CCN2 in tissue repair, scarring and fibrosis. Cytokine Growth Factor Rev 2008; 19: 133-144.

6 Chen MM, Lam A, Abraham JA, Schreiner GF, Joly AH. CTGF expression is induced by TGF- beta in cardiac fibroblasts and cardiac myocytes: a potential role in heart fibrosis. J Mol Cell Cardiol 2000; 32: 1805-1819.

7 Koitabashi N, Arai M, Kogure S, Niwano K, Watanabe A, Aoki Y, Maeno T, Nishida T, Kubota S, Takigawa M, Kurabayashi M. Increased connective tissue growth factor relative to brain natriuretic peptide as a determinant of myocardial fibrosis. Hypertension 2007; 49: 1120-1127.

8 Duisters RF, Tijsen AJ, Schroen B, Leenders JJ, Lentink V, van der Made I, Herias V, van Leeuwen RE, Schellings MW, Barenbrug P, Maessen JG, Heymans S, Pinto YM, Creemers EE. miR-133 and miR-30 regulate connective tissue growth factor. Implications for a role of microRNAs in myocardial matrix remodeling. Circ Res 2009; 104: 170-178. 
9 Nishida M, Sato Y, Uemura A, Narita Y, Tozaki-Saitoh H, Nakaya M, Ide T, Suzuki K, Inoue K, Nagao T, Kurose H. P2Y6 receptor-Galpha12/13 signalling in cardiomyocytes triggers pressure overload-induced cardiac fibrosis. EMBO J 2008; 27: 3104-3115.

10 Ruiz-Ortega M, Rodriguez-Vita J, Sanchez-Lopez E, Carvajal G, Egido J. TGF-beta signaling in vascular fibrosis. Cardiovasc Res 2007; 74: 196-206.

11 Che ZQ, Gao PJ, Shen WL, Fan CL, Liu JJ, Zhu DL. Angiotensin II-stimulated collagen synthesis in aortic adventitial fibroblasts is mediated by connective tissue growth factor. Hypertens Res 2008; 31: 1233-1240.

12 Ahmed MS, Oie E, Vinge LE, Yndestad A, Oystein Andersen G, Andersson Y, Attramadal $\mathrm{T}$, Attramadal $\mathrm{H}$. Connective tissue growth factor-a novel mediator of angiotensin IIstimulated cardiac fibroblast activation in heart failure in rats. J Mol Cell Cardiol 2004; 36: 393-404.

13 Roussel E, Gaudreau M, Plante E, Drolet MC, Breault C, Couet J, Arsenault M. Early responses of the left ventricle to pressure overload in Wistar rats. Life Sci 2008; 82 265-272.

14 Ayada Y, Kusachi S, Murakami T, Hirohata S, Takemoto S, Komatsubara I, Hayashi J, Iwabu A, Ninomiya Y, Tsuji T. Increased expression of biglycan mRNA in pressureoverloaded rat heart. Clin Exp Hypertens 2001; 23: 633-643.

15 Kai H, Mori T, Tokuda K, Takayama N, Tahara N, Takemiya K, Kudo H, Sugi Y, Fukui D, Yasukawa H, Kuwahara F, Imaizumi T. Pressure overload-induced transient oxidative stress mediates perivascular inflammation and cardiac fibrosis through angiotensin II. Hypertens Res 2006; 29: 711-718.

16 Nakamura Y, Yoshiyama M, Omura T, Yoshida K, Izumi Y, Takeuchi K, Kim S, Iwao H, Yoshikawa J. Beneficial effects of combination of ACE inhibitor and angiotensin II type 1 receptor blocker on cardiac remodeling in rat myocardial infarction. Cardiovasc Res 2003; 57: 48-54.

17 Toeda K, Nakamura K, Hirohata S, Hatipoglu OF, Demircan K, Yamawaki H, Ogawa H, Kusachi S, Shiratori Y, Ninomiya Y. Versican is induced in infiltrating monocytes in myocardial infarction. Mol Cell Biochem 2005; 280: 47-56.

18 Korecky B, Rakusan K. Normal and hypertrophic growth of the rat heart: changes in cell dimensions and number. Am J Physiol 1978; 234: H123-H128.

19 Gerdes AM, Liu Z, Zimmer HG. Changes in nuclear size of cardiac myocytes during the development and progression of hypertrophy in rats. Cardioscience 1994; 5: 203-208.

20 Ogawa H, Oohashi T, Sata M, Bekku Y, Hirohata S, Nakamura K, Yonezawa T, Kusachi S, Shiratori Y, Ninomiya Y. Lp3/Hapln3, a novel link protein that co-localizes with versican and is coordinately up-regulated by platelet-derived growth factor in arterial smooth muscle cells. Matrix Biol 2004; 23: 287-298.

21 Hatipoglu OF, Hirohata S, Yaykasli KO, Cilek MZ, Demircan K, Shinohata R, Yonezawa T, Oohashi T, Kusachi S, Ninomiya Y. The 3'-untranslated region of ADAMTS1 regulates its mRNA stability. Acta Med Okayama 2009; 63: 79-85.

22 Nakamura K, Hirohata S, Murakami T, Miyoshi T, Demircan K, Oohashi T, Ogawa H, Koten K, Toeda K, Kusachi S, Ninomiya Y, Shiratori Y. Dynamic induction of ADAMTS1 gene in the early phase of acute myocardial infarction. J Biochem (Tokyo) 2004; 136: 439-446.

23 Demircan K, Gunduz E, Gunduz M, Beder LB, Hirohata S, Nagatsuka H, Cengiz B, Cilek MZ, Yamanaka N, Shimizu K, Ninomiya Y. Increased mRNA expression of ADAMTS metalloproteinases in metastatic foci of head and neck cancer. Head Neck 2009; 31: 793-801.

24 Hatipoglu OF, Hirohata S, Cilek MZ, Ogawa H, Miyoshi T, Obika M, Demircan K, Shinohata R, Kusachi S, Ninomiya Y. ADAMTS1 is a unique hypoxic early response gene expressed by endothelial cells. J Biol Chem 2009; 284: 16325-16333.

25 Yaykasli KO, Oohashi T, Hirohata S, Hatipoglu OF, Inagawa K, Demircan K, Ninomiya Y. ADAMTS9 activation by interleukin 1 beta via NFATc 1 in OUMS-27 chondrosarcoma cells and in human chondrocytes. Mol Cell Biochem 2009; 323: 69-79.

26 Pick R, Jalil JE, Janicki JS, Weber KT. The fibrillar nature and structure of isoproterenol-induced myocardial fibrosis in the rat. Am J Pathol 1989; 134: 365-371.

27 Miyoshi T, Hirohata S, Ogawa H, Doi M, Obika M, Yonezawa T, Sado Y, Kusachi S, Kyo $S$, Kondo S, Shiratori Y, Hudson BG, Ninomiya Y. Tumor-specific expression of the RGDalpha3(IV)NC1 domain suppresses endothelial tube formation and tumor growth in mice. FASEB J 2006; 20: 1904-1906.

28 Berni R, Cacciani F, Zaniboni M, Savi M, Bocchi L, Lapucci S, Razzetti R, Pastore F, Musso E, Stilli D. Effects of the alpha2-adrenergic/DA2-dopaminergic agonist CHF1024 in preventing ventricular arrhythmogenesis and myocyte electrical remodeling, in a rat model of pressure-overload cardiac hypertrophy. J Cardiovasc Pharmacol 2006; 47: 295-302

29 Koten K Hirohata S, Miyoshi T, Ogawa H, Usui S, Shinohata R, Iwamoto M, Kitawaki T, Kusachi S, Sakaguchi K, Ohe T. Serum interferon-gamma-inducible protein 10 level was increased in myocardial infarction patients, and negatively correlated with infarct size. Clin Biochem 2008; 41: 30-37.

30 Yamawaki H, Hirohata S, Miyoshi T, Takahashi K, Ogawa H, Shinohata R, Demircan K, Kusachi S, Yamamoto K, Ninomiya Y. Hyaluronan receptors involved in cytokine induction in monocytes. Glycobiology 2009; 19: 83-92.
31 Miyoshi T, Hirohata S, Uesugi T, Hirota M, Ohnishi H, Nogami K, Hatanaka K, Ogawa H, Usui S, Kusachi S. Relationship between activin A level and infarct size in patients with acute myocardial infarction undergoing successful primary coronary intervention. Clin Chim Acta 2009; 401: 3-7.

32 Sakai S, Miyauchi T, Irukayama-Tomobe Y, Ogata T, Goto K, Yamaguchi I. Peroxisome proliferator-activated receptor-gamma activators inhibit endothelin-1-related cardiac hypertrophy in rats. Clin Sci (Lond) 2002; 103(Suppl 48): 16S-20S.

33 Kuwahara F, Kai H, Tokuda K, Kai M, Takeshita A, Egashira K, Imaizumi T. Transforming growth factor-beta function blocking prevents myocardial fibrosis and diastolic dysfunction in pressure-overloaded rats. Circulation 2002; 106: 130-135.

34 Ogata T, Miyauchi T, Sakai S, Irukayama-Tomobe Y, Goto K, Yamaguchi I. Stimulation of peroxisome-proliferator-activated receptor alpha (PPAR alpha) attenuates cardiac fibrosis and endothelin-1 production in pressure-overloaded rat hearts. Clin Sci (Lond) 2002; 103 (Suppl 48): 284S-288S.

35 McEwan PE, Gray GA, Sherry L, Webb DJ, Kenyon CJ. Differential effects of angiotensin II on cardiac cell proliferation and intramyocardial perivascular fibrosis in vivo. Circulation 1998; 98: 2765-2773.

36 Tokuda K, Kai H, Kuwahara F, Yasukawa H, Tahara N, Kudo H, Takemiya K, Koga M, Yamamoto T, Imaizumi T. Pressure-independent effects of angiotensin II on hypertensive myocardial fibrosis. Hypertension 2004; 43: 499-503.

37 Taniyama Y, Morishita R, Nakagami H, Moriguchi A, Sakonjo H, Shokei K, Matsumoto K, Nakamura T, Higaki J, Ogihara T. Potential contribution of a novel antifibrotic factor, hepatocyte growth factor, to prevention of myocardial fibrosis by angiotensin II blockade in cardiomyopathic hamsters. Circulation 2000; 102: 246-252.

38 Liang B, Leenen FH. Prevention of salt-induced hypertension and fibrosis by AT1-receptor blockers in Dahl S rats. J Cardiovasc Pharmacol 2008; 51: 457-466.

39 Somsen GA, Dubois EA, Brandsma K, de Jong J, van der Wouw PA, Batink HD, van Royen EA, Lie KI, van Zwieten PA. Cardiac sympathetic neuronal function in left ventricular volume and pressure overload. Cardiovasc Res 1996; 31: 132-138.

40 Rodriguez-Vita J, Sanchez-Lopez E, Esteban V, Ruperez M, Egido J, Ruiz-Ortega M. Angiotensin II activates the Smad pathway in vascular smooth muscle cells by a transforming growth factor-beta-independent mechanism. Circulation 2005; 111: 2509-2517.

41 Xia Y, Lee K, Li N, Corbett D, Mendoza L, Frangogiannis NG. Characterization of the inflammatory and fibrotic response in a mouse model of cardiac pressure overload. Histochem Cell Biol 2009; 131: 471-481.

42 Gao DF, Niu XL, Hao GH, Peng N, Wei J, Ning N, Wang NP. Rosiglitazone inhibits angiotensin II-induced CTGF expression in vascular smooth muscle cells-role of PPAR-gamma in vascular fibrosis. Biochem Pharmacol 2007; 73: 185-197.

43 Koitabashi N, Arai M, Niwano K, Watanabe A, Endoh M, Suguta M, Yokoyama T, Tada H, Toyama T, Adachi H, Naito S, Oshima S, Nishida T, Kubota S, Takigawa M, Kurabayashi M. Plasma connective tissue growth factor is a novel potential biomarker of cardiac dysfunction in patients with chronic heart failure. Eur J Heart Fail 2008; 10: 373-379.

44 Tsutsui H, Matsushima S, Kinugawa S, Ide T, Inoue N, Ohta Y, Yokota T, Hamaguchi S, Sunagawa K. Angiotensin II type 1 receptor blocker attenuates myocardial remodeling and preserves diastolic function in diabetic heart. Hypertens Res 2007; 30: 439-449.

45 Duisters RF, Tijsen AJ, Schroen B, Leenders JJ, Lentink V, van der Made I, Herias V, van Leeuwen RE, Schellings MW, Barenbrug P, Maessen JG, Heymans S, Pinto YM, Creemers EE. miR-133 and miR-30 regulate connective tissue growth factor: implications for a role of microRNAs in myocardial matrix remodeling. Circ Res 2009; 104: 170-178, 176p following 178.

46 Panek AN, Posch MG, Alenina N, Ghadge SK, Erdmann B, Popova E, Perrot A, Geier C, Dietz R, Morano I, Bader M, Ozcelik C. Connective tissue growth factor overexpression in cardiomyocytes promotes cardiac hypertrophy and protection against pressure overload. PLoS One 2009; 4: e6743.

47 Zimmermann G, Henle P, Kusswetter M, Moghaddam A, Wentzensen A, Richter W, Weiss S. TGF-betal as a marker of delayed fracture healing. Bone 2005; 36: 779-785.

48 Murawaki Y, Nishimura Y, Ikuta Y, Idobe Y, Kitamura Y, Kawasaki H. Plasma transforming growth factor-beta 1 concentrations in patients with chronic viral hepatitis. J Gastroenterol Hepatol 1998; 13: 680-684.

49 Flisiak R, Maxwell P, Prokopowicz D, Timms PM, Panasiuk A. Plasma tissue inhibitor of metalloproteinases-1 and transforming growth factor beta 1 -possible non-invasive biomarkers of hepatic fibrosis in patients with chronic B and $\mathrm{C}$ hepatitis. Hepatogastroenterology 2002; 49: 1369-1372.

50 el-Agroudy AE, Hassan NA, Foda MA, Ismail AM, el-Sawy EA, Mousa O, Ghoneim MA Effect of angiotensin II receptor blocker on plasma levels of TGF-beta 1 and interstitial fibrosis in hypertensive kidney transplant patients. Am J Nephrol 2003; 23: $300-306$ 